\title{
PENGARUH MODEL PEMBELAJARAN PERSONALIZED SYSTEM OF INSTRUCTION (PSI) DALAM MENINGKATKAN AKTIVITAS DAN HASIL BELAJAR MATEMATIKA SISWA SMA
}

\author{
B Erdiansyah $\mathbf{P}^{*}$, Ika Wirahmad, Gunawan \\ Program Studi Pendidikan Matematika, STKIP Bima \\ *Email korespondensi: yhandecoz@gmail.com
}

\begin{abstract}
ABSTRAK
Penelitian ini dilatarbelakangi oleh rendahnya aktivitas dan hasil belajar matematika siswa salah satu SMA Negeri di Kota Bima. Adapun tujuan dari penelitian ini untuk meningkatkan aktivitas dan hasil belajar matematika siswa dengan menerapkan pembelajaran Personalized System of Instruction (PSI). Jenis penelitian yang digunakan dalam penelitian ini adalah quasi eksperimen, dikatakan begitu karena dalam desain ini peneliti tidak dapat mengontrol semua variabel luar yaitu faktor luar yang tidak diteliti dan menjadi pengganggu sehingga mempengaruhi jalannya eksperimen. Adapun hasil penelitian ini menunjukkan bahwa semua aspek yang dinilai muncul pada saat proses pembelajaran berlangsung. Hal tersebut dilengkapi dengan hasil uji statistik dengan hasil $\mathrm{t}_{\text {hitung }}$ lebih besar dari tabel yaitu 2,86>1,67 dengan perolehan nilai rata-rata hasil belajar kelas eksperimen lebih besar dari kelas kontrol yaitu 65,8 > 53,9. Hal ini berarti bahwa model pembelajaran Personalized System of Instruction (PSI) memberikan hasil yang lebih baik dibandingkan dengan pembelajaran konvensional. Dengan demikian bahwa langkah-langkah model pembelajaran model pembelajaran PSI memberikan pengaruh dalam meningkatkan aktivitas dan hasil belajar matematika siswa.
\end{abstract}

Kata kunci: personalized system of instruction (PSI), hasil belajar dan aktivitas matematika.

\begin{abstract}
This research is motivated by the low activity and learning outcomes of students in one of the public high schools in Bima City. The purpose of this research is to increase students' activities and learning outcomes of mathematics by applying Personalized System of Instruction (PSI) learning. The type of research used in this study is quasi-experimental, it is said that because in this design the researcher cannot control all external variables, namely external factors that are not examined and become a nuisance so that it affects the course of the experiment. The results of this study indicate that all aspects that are assessed appear during the learning process. This is complemented by the results of statistical tests with the results of tcount greater than ttable, namely 2.86 > 1.67 with the acquisition of the average value of learning outcomes in the experimental class which is greater than the control class, which is $65.8>53.9$. This means that the Personalized System of Instruction (PSI) learning model gives better results than conventional learning. Thus, the steps of the PSI learning model have an influence in increasing students' activities and learning outcomes in mathematics.
\end{abstract}

Keywords: personalized system of instruction (PSI), learning outcomes and mathematical activities.

\section{PENDAHULUAN}

Pendidikan dan kemajuan suatu bangsa merupakan satu kesatuan yang tidak dapat dipisahkan. Undang-Undang Nomor 20 Tahun 2003 tentang Sistem Pendidikan Nasional pasal 
1 ayat 1 menyatakan bahwa pendidikan adalah usaha sadar dan terencana untuk mewujudkan suasana belajar dan proses pembelajaran agar peserta didik secara aktif mengembangkan potensi dirinya untuk memiliki kekuatan spiritual keagamaan, pengendalian diri, kepribadian, kecerdasan, akhlak mulia, serta keterampilan yang diperlukan dirinya, masyarakat, bangsa dan Negara.

Berdasarkan undang-undang, tujuan dari pendidikan di Indonesia adalah untuk mewujudkan suasana belajar dan proses pembelajaran aktif agar siswa dapat mengembangkan potensi yang dimiliki. Lebih lanjut Kusumah (2018) mengungkapkan bahwa seorang pendidik dituntut untuk mampu berinovasi menciptakan perangkat pembelajaran yang mampu menumbuhkembangkan kemampuan anak dalam pembelajaran matematika. Ruseffendi (2006) menyatakan bahwa matematika timbul karena pikiran-pikiran manusia yang berhubungan dengan idea, proses, dan penalaran. Hal ini juga didukung oleh (Sowanto dkk, 2019) bahwa program pendidikan matematika dituntut untuk mampu dikembangkan melalui pembelajaran yang mampu menumbuhkembangkan kemampuan berpikir dalam menghadapi kompleksitas dan semakin ketatnya persaingan dunia kerja.

Menurut William Burton yang dikutip oleh Hamalik (2011) "A good learning situation consist of a rich and varied series of learning experiences unified around a vigorous purpose and carried on in interaction with a rich varied and proactive environment". Artinya situasi belajar yang baik terdiri dari serangkaian kata dan beragam pengalaman belajar yang bersumber dari tujuan yang kuat dan saling berinteraksi dengan lingkungan yang kaya akan variasi dan kemampuan. Sehingga pemilihan pembelajaran yang mengarahkan pada keaktifan siswa akan sangat menentukan dalam keberhasilan pembelajaran. Salah satu yang bisa dipilih oleh guru adalah dengan pembelajaran Personalized System of Instruction (PSI). Personalized System of Instruction (PSI) merupakan metode yang dikembangkan oleh Fred S. Keller (1968), pada awalnya dikenal dengan nama The Keller Plan". Personalized System of Instruction (PSI) memberikan kesempatan kepada siswa untuk maju menurut kecepatan masing-masing (self paced learning) dalam menguasai unit-unit yang sedang dipelajari (Nasution, 2010).

Ruseffendi (2006) menyatakan bahwa: Personalized System of Instruction (PSI) memungkinkan adanya aspek personal sekaligus aspek sosial dalam proses pendidikan. Peran guru dalam pembelajaran Personalized System of Instruction (PSI) adalah sebagai 
pembimbing, fasilitator, dan motivator. Tuwu (1993) menegaskan bahwa: "Proses pembelajaran dengan metode personalized system of instruction (PSI) adalah bentuk pembelajaran dimana guru berupaya menempatkan dirinya sebagai pengayom, narasumber, pembimbing atau pendamping dan teman belajar anak yang dilandasi dengan pendekatan sesuai dengan filosofis tutwuri handayani yang di tunjang oleh fasilitas belajar yang relevan dan memadai seperti LKS, Alat Peraga, buku dan media lain”. Personalized System of Instructions (PSI) merupakan pembelajaran berbasis personal atau individu siswa yang sudah dimodifikasi dengan sistem cooperative learning. Hal ini didukung oleh Mulyadin dkk (2020) bahwa pemahaman siswa seharusnya ditanamkan melalui keaktifan siswa dalam pembelajaran. Oleh karenanya PSI merupakan pembelajaran yang menggunakan sistem modular dimana siswa dibantu oleh seorang tutor yang dapat berupa guru atau teman satu kelasnya (Modjiono, 2002).

Ali (2008) menjelaskan bahwa metode Personalized System of Instruction (PSI) memiliki ciri-ciri sebagai berikut : (a). Memungkinkan siswa maju menurut kemampuan masing-masing (self paced learning); (b). Adanya persyaratan penguasaan yang sempurna bagi setiap unit pelajaran sebelum maju ke unit pelajaran berikutnya; (c). Menggunakan kuliah dan demonstrasi sebagai alat untuk memberikan motivasi kepada siswa; (d). Komunikasi guru siswa ditekankan pada penggunaan bahan-bahan tertulis dalam bentuk programa; (e). Menggunakan sistem proctor, yakni pemberian tes secara berulang-ulang untuk memberikan penilaian secara cepat dan sebagai umpan balik (feedback) bagi pemberian bantuan bagi siswa yang membutuhkan; (f). Menggunakan siswa tutor, yakni siswa pandai memberi bimbingan belajar kepada siswa yang kurang atau yang lemah, sehingga seluruh siswa dapat mencapai taraf penguasaan penuh terhadap unit pelajaran yang dipelajari; dan (g). Memungkinkan adanya aspek personal dan sosial dalam proses pendidikan. Dengan bahan-bahan tertulis aspek-aspek pribadi atau personal dapat memperoleh perhatian khusus, sedangkan dengan menggunakan kuliah dan demonstrasi dapat diperhatikan aspek sosial siswa.

\section{METODE PENELITIAN}

Penelitian ini merupakan penelitian quasi eksperimen, dikatakan begitu karena dalam desain ini peneliti tidak dapat mengontrol semua variabel luar yaitu faktor luar yang tidak diteliti dan menjadi pengganggu sehingga mempengaruhi jalannya eksperimen. Rancangan penelitian adalah mengatur strategi dalam menggunakan metode, alat serta analisis data sesuai 
dengan gejala atau variabel yang diteliti, sehingga tujuan penelitian dapat tercapai dengan efisien dan efektif (Arikunto ,2010).

Pada penelitian ini, kelas eksperimen merupakan kelompok siswa yang mendapat pembelajaran dengan Personalized System of Instructions (PSI) dan kelas kontrol merupakan kelompok siswa yang mendapat pembelajaran biasa. Adanya kelas kontrol ini adalah sebagai pembanding, sejauh manakah terjadi perubahan akibat perlakuan terhadap kelas eksperimen. Adapun desain penelitian ini adalah sebagai berikut:

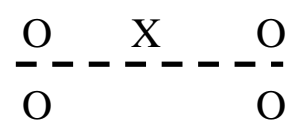

\section{Keterangan:}

O : Pre-test atau post-test aktivitas dan hasil belajar matematika siswa

$\mathrm{X} \quad$ : Pembelajaran dengan Personalized System of Instructions (PSI)

- - - : Subjek penelitian tidak dikelompokkan secara acak.

Sampel pada penelitian ini hanya mengambil dua kelompok yaitu kelompok untuk kelas eksperimen dan kelompok untuk kelas kontrol. Dengan pertimbangan mendapatkan materi yang X PMIA 1 sebagai kelas eksperimen dan X PMIA 2 sebagai kelas kontrol. Instrumen pembelajaran yang digunakan dalam penelitian ini ada dua yaitu lembar observasi dan mode test.

\section{HASIL DAN PEMBAHASAN}

Dalam penelitian ini, digunakan instrument berupa lembar observasi dan soal tes (essay). Sebelum tes digunakan terlebih dahulu harus diuji untuk mengetahui validitas, reabilitas, daya pembeda dan indeks kesukaran suatu tes. Selanjutnya sampel akan diberikan pre-test dan post-test untuk mengetahui adanya pengaruh model pembelajaran terhadap hasil belajar siswa melalui uji normalitas, uji homogenitas, dan uji hipotesis. 


\section{Hasil}

Uji normalitas

Perhitungan Uji normalitas data post-test menggunakan rumus Chi-Kuadrat sehingga diperoleh hasil yang tercantum pada Tabel 1 sebagai berikut :

Tabel 1: Nilai Chi Kuadrat ( $\chi 2)$ kelas eksperimen dan kelas kontrol

\begin{tabular}{cccc}
\hline & $\begin{array}{c}\text { Chi } \\
\text { Kuadrat } \\
\text { (hitung) }\end{array}$ & $\begin{array}{c}\text { Chi } \\
\text { Kuadrat } \\
\text { (tabel) }\end{array}$ & Keterangan \\
\hline Eksperimen & 9,604 & 11,070 & Terdistribusi normal \\
Kontrol & 3,626 & 11,070 & Terdistribusi normal \\
\hline
\end{tabular}

Berdasarkan tabel diatas maka hasil uji normalitas $\left(x_{\text {Hitung }}^{2}\right)<\left(x_{\text {Tabel }}^{2}\right.$, atau $\left(x_{\text {Tabel }}^{2}\right)>\left(x_{\text {Hitung }}^{2}\right)$. maka dapat disimpulkan data pos-ttest untuk kedua kelas tersebut Berdistribusi Normal.

\section{Uji Homogenitas}

Pengujian dilakukan dengan maksud untuk mengetahui apakah sebaran data homogen atau tidak. Kriteria pengujian yang dilakukan pada taraf signifikan 5\% (uji Fisher) . Sampel akan dinyatakan homogen jika $\mathrm{F} \_$hitung $<\mathrm{F} \_$tabel. Berikut ini adalah hasil dari perhitungan uji Homogenitas yaitu :

Tabel 2: Nilai Uji Homogenitas kelas eksperimen dan kelas kontrol

\begin{tabular}{ccc}
\hline & $F$ (hitung) & $F$ (tabel) \\
\hline Uji Fisher & 1,005 & 1,762
\end{tabular}

Dari tabel diatas diperoleh $F_{\text {hitung }}$ sebesar 1,005 dan $F_{\text {tabel }}$ sebesar 1,762 untuk data pretest. Berdasarkan hasil tersebut dapat disimpulkan bahwa kedua kelas berasal dari sampel yang homogen, karena $F_{\text {hitung }} \leq F_{\text {tabel }}$ 


\section{Uji Hipotesis}

Hasil Perhitungan analisis nilai posttest kelompok kontrol dapat dilihat bahwa pada soal pre-test siswa mendapatkan nilai terendah 30 dan tertinggi 47 dengan nilai rata-rata 37,9 sedangkan pada soal post-test kelompok eksperimen mendapatkan nilai terendah 45 dan nilai tertinggi 83 dengan nilai rata-rata 65,8, dapat dilihat pada tabel berikut.

Kemudian diperoleh hasil Uji hipotesis $\mathrm{t}_{\text {hitung }}=2,86$ dengan harga pada taraf signifikan $5 \%$ untuk uji dua pihak dengan $\mathrm{dk}=+-2=30+31-2=59$, harga $\mathrm{t}_{\text {tabel }}=1,67$.

Tabel 3. Hasil Observasi Aktivitas dan Hasil Evaluasi Belajar Siswa

\begin{tabular}{cccccccc}
\hline \multirow{2}{*}{ Kelas } & \multicolumn{2}{c}{$\begin{array}{c}\text { Aktivitas Belajar } \\
\text { Siswa }\end{array}$} & \multicolumn{2}{c}{ Hasil Belajar Siswa } & Ketuntasan \\
\cline { 2 - 6 } & $\begin{array}{c}\text { Rata-rata } \\
\text { Skor }\end{array}$ & Kategori & $\begin{array}{c}\text { Nilai } \\
\text { Terendah }\end{array}$ & $\begin{array}{c}\text { Nilai } \\
\text { Tertinggi }\end{array}$ & $\begin{array}{c}\text { Nilai } \\
\text { Rata-rata }\end{array}$ & Uji \\
\hline Eksperimen & 30,6 & $\begin{array}{c}\text { Sangat } \\
\text { Aktif }\end{array}$ & 45 & 83 & 65,8 & $83,7 \%$ & 2,86 \\
Kontrol & 24,8 & Aktif & 30 & 57 & 53,9 & $63,38 \%$ & \\
\hline
\end{tabular}

Dari tabel diatas menunjukan bahwa nilai $\mathrm{t}_{\text {hitung }}>\mathrm{t}_{\text {tabel }}(2,86>1,67) \mathrm{H}_{0}$ ditolak dengan demikian $\mathrm{H}_{\mathrm{a}}$ diterima. Jadi dapat disimpulkan bahwa penggunaan model pembelajaran Personalized System of Instruction (PSI) berpengaruh dan signifikan terhadap hasil belajar siswa pada materi sistem persamaan linear tiga variabel. Hasil penilaian menunjukkan bahwa semua aspek yang dinilai muncul pada saat proses pembelajaran berlangsung. Hal tersebut menyatakan bahwa langkah-langkah model pembelajaran telah dilaksanakan dengan baik.

\section{Pembahasan}

Dalam pelaksanaan proses pembelajaran kelas eksperimen dengan menerapkan kombinasi strategi pembelajaran Personalized System Of Instruction (PSI) siswa dikelompokkan dalam beberapa kelompok kecil. Dengan kata lain, proses pembelajaran menggunakan kombinasi strategi pembelajaran Personalized System Of Instruction (PSI) sangat mengoptimalkan partisipasi siswa, sehingga siswa lebih memahami materi pelajaran dan hasil belajar yang diperolehpun akan meningkat. Pada proses pembelajaran setelah diberikan perlakuan, maka untuk kelas eksperimen dan kelas kontrol diberikan post-test yang bertujuan untuk mengetahui ada atau tidaknya pengaruh terhadap hasil belajar setelah diberikannya perlakuan. Pada penerapan kombinasi strategi pembelajaran Personalized System Of Instruction 
(PSI), siswa dituntut aktif, secara maksimal melibatkan seluruh kemampuan peserta didik untuk mencari dan menyelidiki secara sistematis

\section{KESIMPULAN}

Berdasarkan hasil penelitian maka dapat ditarik kesimpulan bahwa model pembelajaran model pembelajaran Personalized System Of Instruction (PSI) memberikan hasil yang lebih baik dibandingkan dengan pembelajaran konvensional. Hal tersebut dibuktikan dengan hasil $\mathrm{t}_{\text {hitung }}$ lebih besar dari $\mathrm{t}_{\text {tabel }}$ yaitu 2,86 > 1,67 dengan perolehan nilai rata-rata hasil belajar kelas eksperimen lebih besar dari kelas kontrol yaitu 65,8 > 53,9. Hal ini disebabkan oleh suasana pembelajaran dengan model pembelajaran kooperatif tipe Personalized System Of Instruction (PSI) memotivasi peserta didik untuk aktif sejak awal dalam proses pembelajaran serta membudayakan sifat berani bertanya. Dengan kata lain, terdapat pengaruh model pembelajaran Personalized System Of Instruction (PSI) dalam meningkatkan aktivitas dan hasil belajar siswa pada materi sistem persamaan linear tiga variabel kelas $\mathrm{X}$ salah satu SMA Negeri di Kota Bima tahun pelajaran 2020/2021.

\section{REKOMENDASI}

Penelitian ini, diharapkan dapat berguna untuk kemajuan pendidikan khususnya dalam bidang pendidikan matematika. Guru dapat memadukan model pembelajaran Personalized System Of Instruction (PSI) ini dengan model lain sesuai kebutuhan pembelajaran di dalam kelas sehingga materi dapat tersampaikan dengan baik.

\section{UCAPAN TERIMAKASIH}

Ucapan terima kasih kepada pihak salah satu SMA Negeri tempat dilaksanakan penelitian di Kota Bima mulai dari kepala sekolah sampai guru-guru beserta staf yang telah banyak membantu dalam kegiatan penelitian yang dilakukan. Serta Pihak-pihak berkontribusi dalam diskusi atau pengolah data yang terkait langsung dengan penelitian/penulisan.

\section{REFERENSI}

Arikunto, S. (2010). Penelitian Suatu Pendekatan dan Praktek. Jakarta: PT Rineka Cipta.

Hamalik, O. (2001). Proses belajar mengajar. 
Indonesia, P. R. (2003). Undang-Undang Republik Indonesia Nomor 20 Tahun 2003 Tentang Sistem Pendidikan Nasional.

Indonesia, S. B. Ali, Muhammad.(2008). Guru dalam Proses Belajar Mengajar. Bandung: Sinar Baru Algesindo. Arikunto, S.(2013). Propsedur Penelitian Suatu Pendekatan Praktik. Jakarta: Rineka Cipta Dalman.(2014). Keterampilan Menulis. Jakarta: Raja Grafindo Persada.

Kusumah, Y. S. (2018, May). Enhancing students' mathematical representation and selfefficacy through situation-based learning assisted by geometer's sketchpad program. In Journal of Physics: Conference Series (Vol. 1013, No. 1, p. 012107). IOP Publishing.

Mudjiono. (2002). Belajar dan Pembelajaran. Jakarta. Depdikbud

Mulyadin, E., Sowanto, S., \& Dusalan, D. (2020). Pengembangan Perangkat Pembelajaran CIRC (Cooperative Integrated Reading and Composition) dalam Meningkatkan Pemahaman Matematis Pada Materi Perbandingan Siswa SMP. SUPERMAT (Jurnal Pendidikan Matematika), 4(1), 40-51.

Nasution, S. (2000). Berbagai pendekatan dalam proses belajar dan mengajar.

Ruseffendi, E. T. (2006). Pengantar kepada membantu guru mengembangkan kompetensinya dalam pengajaran matematika untuk meningkatkan CBSA. Bandung: tarsito.

Sowanto, S., Andang, A., Mutmainnah, M., \& Saputra, H. A. (2019). Kemampuan SelfEfficacy Mahasiswa Melalui Bahan Ajar Metode Statistika Menggunakan Hybrid Learning Pada Tantangan Revolusi Industri 4.0. Supermat (jurnal pendidikan matematika), 3(2), 65-73.

Tuwu, A. (1993). Pengantar Metode Penelitian. Jakarta: Universitas Indonesia. 